\title{
Parasitäre Immunmodulation: von Mäusen und Menschen
}

\author{
AnNa-Maria DitTrich ${ }^{1}$, ECKard Hamelmann ${ }^{2}$ \\ ${ }^{1}$ Nachwuchsgruppe SFB 587, Medizinische Hochschule Hannover; ${ }^{2}$ Klinik für Kinder- und Jugendmedizin, St.-Josef-Hospital, Ruhr-Universität \\ Bochum
}

Allergo J 2009;18: 190-5

Parasites and allergies: from mice to men
Auf Seite 193 dieses Beitrags, der in Ausgabe 3/2009 von Allergo Journal abgedruckt wurde, hatte sich ein Fehler eingeschlichen. In der Abbildung 1 ist bei der Wiedergabe der TFG- $\beta$-positiven regulatorischen T-Zellen der F+/OVA/OVA-Gruppe (rechts unten) eine falsche Darstellung eingefügt worden.

Die Abbildung 1 ist nachfolgend nochmals korrekt wiedergegeben. Autoren, Herausgeber und Redaktion bitten den Fehler zu entschuldigen.

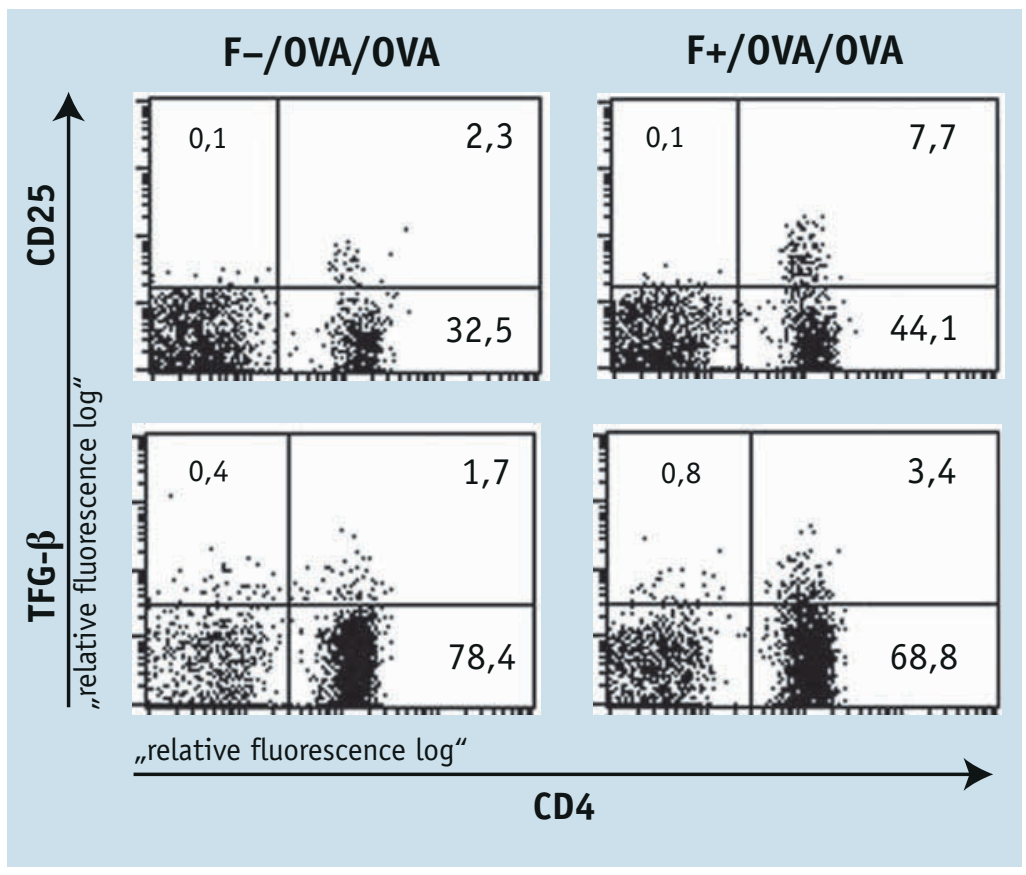

Abbildung 1. Infektion mit dem Filarienparasiten Litomosoides sigmodontis erhöht die Anzahl systemischer regulatorischer T-Zellen. Tiere, die mit dem Parasiten Litomosoides sigmodontis (F) infiziert und mit Ovalbumin (OVA) sensibilisiert und provoziert wurden ( $F+/ O V A / O V A)$, zeigten erhöhte Prozentzahlen $\mathrm{CD}_{4}^{+} / \mathrm{CD}_{25}{ }^{+}$und $\mathrm{CD}_{4}{ }^{+} / \mathrm{TGF}-\beta^{+}$regulatorischer T-Zellen in der Milz und den drainierenden Lymphknoten (nicht gezeigt) im Vergleich zu Tieren ohne parasitäre Infektion (F-/OVA/OVA). 